\title{
Biography: Sylvia Weiner, MD, PhD
}

\section{Department of Obesity and Metabolic Surgery, Krankenhaus Nordwest, Frankfurt am Main, Germany}

\section{Sonja Chiappetta ${ }^{1}$ (D)}

Published online: 10 June 2020

(C) Springer Science+Business Media, LLC, part of Springer Nature 2020

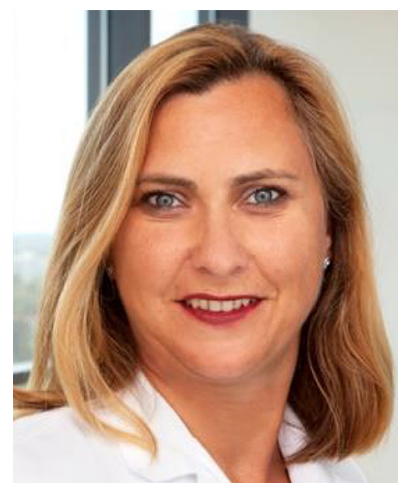

Dr. Sylvia Weiner is the perfect role model for young female surgeons. She is a wife, mother, head of department and internationally recognized surgeon. Dr. Weiner was born in Zschopau, Saxony, Germany, the first daughter of Dr. Rudolf Alfred Weiner, a surgeon, and Dr. Carla Weiner, an anesthesiologist. Both parents were great influences on her and played major roles in her choice of a career.

Sylvia entered medical school at the University of Würzburg in 1998 and graduated in 2005 from the University of Gießen. At the age of 21, Sylvia performed her first bariatric internship with Dr. Paul O'Brien (Melbourne, Australia), and in 2003, she was a minimally invasive surgery fellow with Dr. Michel Gagner at the Mount Sinai Hospital in New York City. Sylvia Weiner also earned a Ph.D. Her thesis was about Quality of Life (University of Witten/Herdecke, Prof. Edmund Neugebauer) and the fundamentals for The Bariatric Quality of Life Index: a measure of well-being in obesity surgery patients (Obes Surg 2005).

Sonja Chiappetta

drschiappetta@gmail.com

1 Obesity and Metabolic Surgery Unit, Ospedale Evangelico Betania, Via Argine 604, 80147 Naples, Campania, Italy
After graduation, Sylvia started her surgical career under the leadership of her father, Prof. Rudolf A. Weiner, the head of the Department of General Surgery at Krankenhaus Sachsenhausen, Frankfurt am Main, Germany. It was the first department in Germany to receive both national and international Centre of Excellence in Bariatric Surgery certifications. Sylvia married Detlef Weis in 2007 and immediately became the mother of his two children, Viktoria and Carli. During her residency, Sylvia had 2 children of her own, Sophia (2008) and Raphael (2011). Despite being the mother of 4 children, she still managed to complete her general surgical training. Additionally, she gained her specialization in emergency medicine, and from 2008 to 2012, she assisted in reconstructive plastic surgeries.

In 2014, Sylvia moved to Krankenhaus Bad Soden to complete her residency training and performed the whole spectrum of general vascular and thoracic surgery. In November of that year, Sylvia moved to Krankenhaus Nordwest in Frankfurt am Main to train under the headship of Prof. Thomas W. Kraus.

In the 1990s, Sylvia's father, Rudolf Weiner, performed the first adjustable gastric banding and gastric bypass in Germany. He worked alongside Raul Rosenthal, as a senior surgeon in this hospital. As a result of these efforts, the Nordwest Krankenhaus became the first center for bariatric surgery in Germany. However in 2001, Dr. Rudolf Weiner left the hospital to become the head of the Department in Krankenhaus Sachsenhausen. Although she was specializing in general surgery, Sylvia took it upon herself to revive the bariatric surgery at the Nordwest Krankenhaus hospital. With her unstoppable power, hard work, and the typical "Weiner" character, she succeeded. In 2015, she started bariatric surgery and did 26 bariatric surgeries her first year. The number of bariatric surgical cases slowly increased, 57 cases in 2016 and 82 cases in 2017. In 2018, she further specialized in visceral surgery and became the head of the bariatric surgery unit which soon became a recognized German bariatric center 
(CAADIP, Kompetenzzentrum). In 2019, Sylvia became the head of the Department for Obesity and Metabolic Surgery, currently leading a team of 30 including secretaries, nutritionists, physiotherapists, and bariatric nurses. The multidisciplinary approach is fundamental in her bariatric center. In 2019, Sylvia and her surgical team (2,25 senior consultants, 5 residents) performed 279 primary bariatric surgeries and 496 total surgeries. They applied for the Center of Excellence designation and will hopefully be awarded it in 2020. Sylvia motivates her team with strict skills and structure but has a great mother heart for everyone.

In addition to leading the bariatric program at the Krankenhaus Nordwest, Sylvia is recognized on the international stage. Since 2002, she has assisted her father in organizing the highly successful biannual, Frankfurter Meeting.
Recently, she took over as the meeting President. This year, at the 11th Frankfurter Meeting (19-20 November 2020), she will welcome again the whole IFSO family and will continue to follow her father's passion for obesity and metabolic surgery. Sylvia has also seen her participation in IFSO steadily increase. In 2012, she implemented the first YOUNG IFSO session, and she is asked to speak at the annual meeting yearly.

Sylvia is the perfect role model for all young surgeons, because she has demonstrated that with hard work and determination one can succeed at both work and family.

Publisher's Note Springer Nature remains neutral with regard to jurisdictional claims in published maps and institutional affiliations. 